\title{
AVALIABILIDADE DO PROGRAMA SAÚDE NA ESCOLA NO NORDESTE DO BRASIL
}

EVALUABILITY OF THE SCHOOL HEALTH PROGRAM IN NORTHEASTERN

BRAZIL

EVALUACIÓN DEL PROGRAMA SALUD EN LA ESCUELA EN EL NORDESTE DE

BRASIL

Maria Socorro de Araújo Dias ${ }^{1}$

Lielma Carla Chagas da Silva ${ }^{2}$

Maria da Conceição Coelho Brito ${ }^{3}$

Alexandro do Vale Silva ${ }^{4}$

Rayanne Branco dos Santos Lima ${ }^{5}$

Diógenes Farias Gomes 6

Angelo Brito Rodrigues ?

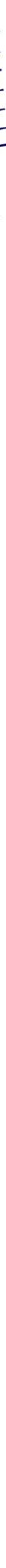




\section{ABSTRACT}

The objective is to analyze the evaluability of the School Health Program in Ceará, from the Logical Model and Analysis and Judgment Matrix. evaluability study of qualitative approach, carried out from August 2012 to August 2015 by documentary analysis of 32 documents Program and semi-structured interviews with 13 key informants from 13 cities of three Ceará health macro-regions. The results of the Logical Model feature that intersectoral coordination is weakened in the 13 cities, and only the actions of nutrition and ophthalmologic evaluations are conducted more frequently (in 10 and 8 cities, respectively). Other important actions of the program occur between 6 and 1 cities. Actions on psychosocial assessment are absent, promoting physical activity and tobacco control and other cancer factors in all cities. Dialoging with the Logic Model, the Analysis Matrix and Judgment points 23,3\% of implementation of the School Health Program in Ceara, the incipient indicative of this.

\section{RESUMEN}

Se pretende analizar la evaluación del Programa Salud en la Escuela en Ceará, a partir del Modelo Lógico y de la Matriz de Análisis y Juicio. Estudio de evaluación, de abordaje cualitativo, realizado de agosto de 2012 a agosto de 2015, mediante análisis documental con 32 documentos del Programa y entrevistas semiestructuradas con 13 informantes clave de 13 municipios de tres macrorregiones de salud de Ceará. Los resultados del Modelo Lógico presentan que la articulación intersectorial es fragilizada en los 13 municipios, y que sólo las acciones de evaluación nutricional y oftalmológica se realizan más frecuentemente (en 10 y 8 municipios, respectivamente). Otras acciones importantes del Programa ocurren entre 6 y 1 municipios. Se están ausentes las acciones sobre evaluación psicosocial, promoción de la actividad física, y control del tabaquismo y otros factores de cáncer en todos los municipios. Dialogando con el Modelo Lógico, la Matriz de Análisis y Juicio apunta el 23,3\% de implantación del Programa Salud en la Escuela en Ceará, indicativo de la incipiente de ésta.

\section{INTRODUÇÃO}

Dentre os esforços para materialização de uma política intersetorial no Estado brasileiro envolvendo os setores da saúde e da educação, destaca-se o Programa Saúde na Escola (PSE). Instituído pelo decreto presidencial n. 6.286, de 05 de dezembro de 2007, este Programa é resultado do trabalho integrado entre os Ministérios da Saúde (MS) e o da Educação (MEC), na perspectiva de ampliar as ações de saúde aos alunos da rede pública de ensino ${ }^{1}$.

0 PSE se propõe a ser um novo desenho de política de educação em saúde. Compreende as áreas saúde e educação de forma integral e parte de uma formação ampla para a cidadania e usufruto pleno dos direitos humanos, de forma a promover também a articulação de saberes, a participação de alunos, pais, comunidade escolar e sociedade em geral na construção e controle social da política².

Para sua operacionalização, o PSE apresenta cinco componentes: 1) avaliação clínica e psicossocial; 2) ações de promoção da saúde e prevenção das doenças e agravos; 3) educação permanente e capacitação de profissionais da educação e saúde e de jovens para o PSE; 4) monitoramento e avaliação da saúde dos estudantes; e, 5) monitoramento e avaliação do PSE. 0 quinto componente sinaliza a necessária inclusão de processos avaliativos para o desenvolvimento do $\mathrm{PSE}^{2}$.

0 PSE encontra-se em desenvolvimento. Concernente ao proposto no quinto componente desse Programa é que se propõe realizar um estudo de avaliabilidade para verificar em que medida o PSE pode ser avaliado ${ }^{3}$. Estudos de avaliabilidade são importantes por subsidiarem gestores no processo de avaliação de programas, de modo a reunir informações para a tomada de decisões sobre a continuidade destes. Permite, assim, que a avaliação tenha objetividade necessária para tornar o processo factível dentro do tempo e dos recursos disponiveis, mesmo que para isso seja necessário simplificar processos, limitar a profundidade do estudo e relativizar a precisão e a abrangência dos resultados, preservando o que the é essencial: a contribuição para a tomada de decisão e para sua implementação ${ }^{4}$.

No Ceará, em 2012, 161 municípios receberam incentivo federal para que, em 298 escolas estaduais e 4.431 municipais, fossem desenvolvidas ações para reforçar o cuidado e a promoção à saúde dos alunos, incluindo ações concretas para o enfrentamento de doenças crônicas não transmissíveis ${ }^{5}$.

Desse modo, este artigo objetiva realizar uma análise da avaliabilidade do Programa Saúde na Escola no estado do Ceará. 


\section{METODOLOGIA}

Estudo de avaliabilidade ${ }^{6}$, de abordagem qualitativa, realizado no período de agosto de 2012 a agosto de 2015, em 13 municípios de três macrorregiões de saúde do Ceará.

Os municípios pesquisados de cada macrorregião de saúde foram identificados considerando a classificação, por porte populacional, utilizada pelo Instituto de Pesquisa e Estratégia Econômica do Ceará (IPECE): pequeno porte I (até 20.000), pequeno porte II (20.001 a 50.000), médio porte (50.001 a 100.000), grande porte $(100.001$ a 900.000) e metrópole $(>900.000)^{7}$.

Houve, então, a associação dos critérios de base populacionais antes mencionados com a configuração do processo de regionalização da saúde vigente no período da coleta de dados. 0 Ceará, em tal momento, apresentava o Sistema Estadual de Saúde estruturado em três (03) macrorregionais: Fortaleza, Sobral e Cariri $^{8}$. Assim, compuseram o cenário do estudo 13 municípios cearenses.

Para o alcance do objetivo do estudo, a coleta de informações procedeu-se da seguinte forma:

1. Realizou-se uma busca nos sítios eletrônicos do Ministério da Saúde e da Educação com vistas a identificar documentos que regulamentavam o PSE. Chegou-se ao número de 32 documentos de cunho normativos, informativos e educativos. Essa análise foi guiada por perguntas-chave para a construção de programas e políticas, que incluíam aspectos sobre a criação, finalidade e operacionalização do Programa ${ }^{9}$.

2. Entrevistas semiestruturadas com 13 informantes-chave, representados pelos coordenadores municipais do Programa. Foram abordados questionamentos acerca da apropriação do Programa pelo município, sua operacionalização e desafios.

As etapas 1 e 2 foram necessárias para a construção do Modelo Lógico-ML do PSE no Ceará. Esse processo teve por finalidade delinear o Programa, e a busca pela coerência com o que estava sendo implementado e o que era previsto.

1. Oficina de validação do ML com um representante de cada macrorregião. Para essa etapa utilizou-se como critérios: maior tempo de implantação do Programa no município, coordenador com exercício na função há mais de um ano e a disponibilidade para participação.

2. Realinhamento do ML mediante o julgamento realizado na etapa 3. Essa etapa almejou detalhar o

\section{Os critérios ou indicadores foram representados pelas ações desempenhadas pelo PSE...}

Programa em termos de seus componentes e de sua forma de operacionalização, identificando todas as ações e produtos necessários aos resultados esperados. 0 ML foi reapresentado aos informanteschave que validaram o conteúdo e as relações estabelecidas entre os elementos expostos.

3. A partir do ML procedeu-se à construção da Matriz de Análise e Julgamento, também chamada de Matriz Final da Avaliação, cuja função é avaliar o desempenho do Programa ${ }^{10}$. Esta foi construída considerando o que do Programa deve ser avaliado e com base em que parâmetros isto deve ser feito. Para isso, elencaram-se para cada componente extraído do ML os critérios, os indicadores e os padrões que foram utilizados na mensuração dos dados. 0s critérios ou indicadores foram representados pelas ações desempenhadas pelo PSE nos municípios pesquisados, haja vista que estas atividades devem ser operacionalizadas para o alcance dos resultados do programa.

Os padrões foram adotados e discutidos a partir das indicações dos documentos legais e estudos afins disponivel na literatura. 0 parâmetro ou padrão consistiu num valor de referência para mensuração de um fenômeno ou objeto, considerado como ideal, podendo ou não ser expresso numericamente ${ }^{11}$. A definição dos padrões da Matriz de Análise e Julgamento foi delimitada tendo como base a normatização proposta nos documentos oficiais e nos produtos das entrevistas.

A Matriz foi, posteriormente, submetida à apreciação de um comitê de especialistas formados por três profissionais da área acadêmica, que também são vinculados aos serviços de saúde e desenvolvem suas atividades na atenção primária à saúde. As observações do comitê de especialistas foram incorporadas, os valores dos referenciais padrões foram consolidados e os resultados devidamente calculados para que a matriz de critérios e julgamentos fosse validada. 
0 estudo atendeu aos princípios éticos das diretrizes e normas regulamentadoras para pesquisa envolvendo seres humanos, por meio da Resolução n 466 de 12 de dezembro de 2012. A pesquisa foi aprovada pelo Comitê de Ética em Pesquisa da Universidade Estadual Vale do Acaraú - UVA, sob Parecer N. 212.998/2013.

\section{RESULTADOS E DISCUSSÃO}

Os resultados do estudo estão organizados mediante apresentação, análise e discussão do Modelo Lógico do PSE no Ceará e da Matriz de Análise e Julgamento.

\section{Modelo Lógico do PSE no Ceará}

0 ML do PSE no estado do Ceará (Figura 1) mostra os componentes, recursos, ações, produtos, resultados intermediários e resultado final. A análise documental e as entrevistas evidenciaram que no estado as ações se desdobram a partir dos componentes: avaliação clínica e psicossocial; promoção da saúde e prevenção de doenças; e educação permanente e capacitação de profissionais da educação e da saúde e de jovens. 0 ML ainda considera fatores apontados pelos informantes-chave como aqueles que interferem no processo de implantação do PSE, e que se tornam desafios que permeiam a operacionalização do Programa.

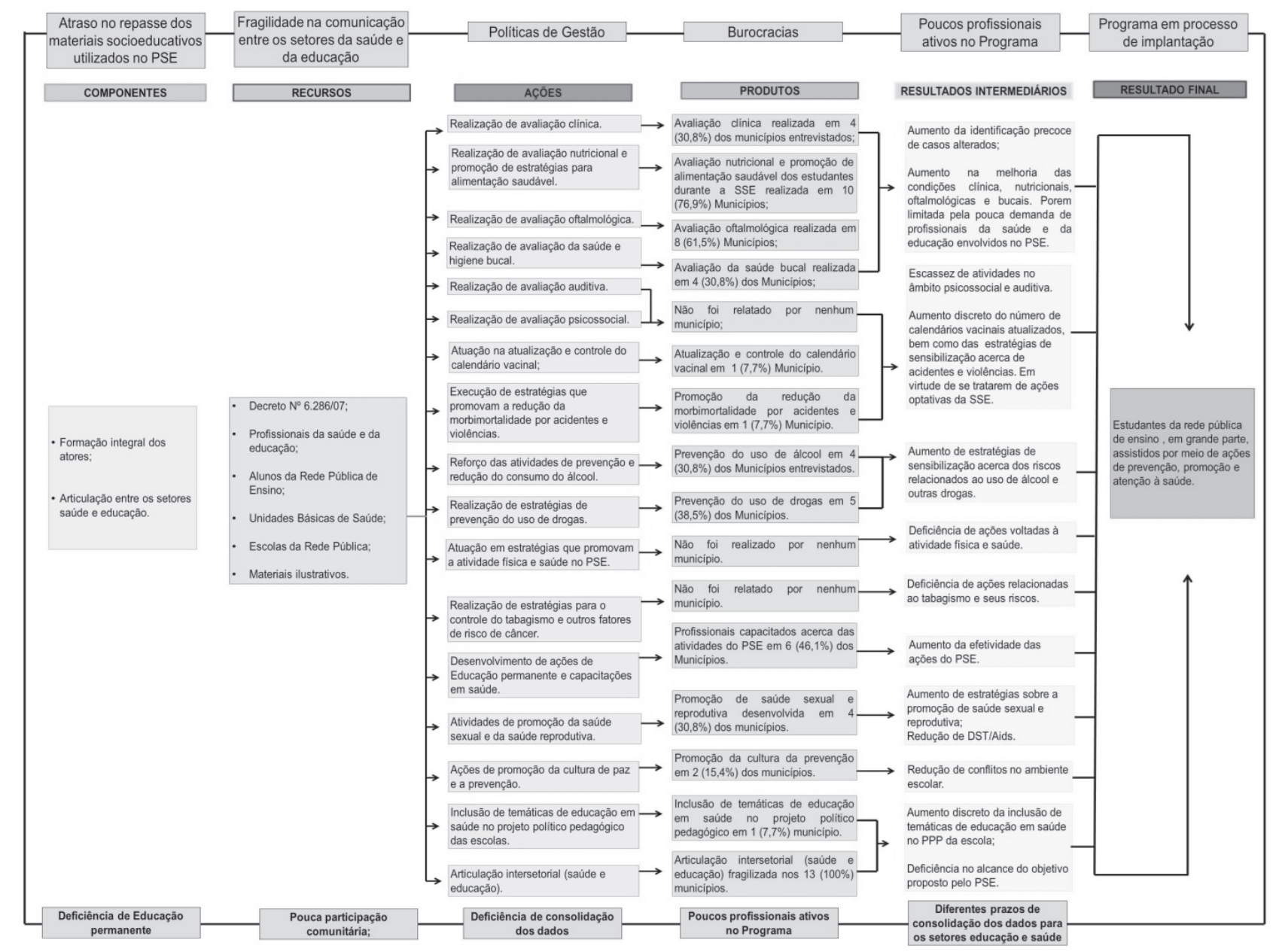

Fonte: dados do estudo.

Analisando o ML, verifica-se a menção da avaliação clínica como realizada em quatro (04) dos municípios analisados. Tal dado se repete quando relacionado à avaliação de saúde bucal, ações para prevenção do uso do álcool e para atividades direcionadas para a promoção da saúde sexual e reprodutiva. 0s produtos identificados demonstram a necessidade de mais investimentos nesses campos, inferindo que intervir neles colabora para o retardamento, controle e até não ocorrência de situações de alto custo para o sistema de saúde brasileiro e que 
repercutem no desenvolvimento educacional e na qualidade de vida do aluno, a exemplo de distúrbios nutricionais, infecções recorrentes, gravidezes indesejadas que elevam a incidência de abortos clandestinos, e os acidentes de trânsitos fatais ou com severas sequelas.

Com relação à promoção da redução da morbimortalidade por acidentes e violências, um (01) município sinalizou desenvolver atividades para esse fim. Os acidentes e violências impõem uma carga negativa na qualidade de vida das pessoas. À saúde pública compete zelar por comunidades seguras e sadias, estabelecendo planos e políticas nacionais para prevenir os acidentes e violências, realizando parcerias entre os vários setores e assegurando dotação de recursos para as ações preventivas ${ }^{12}$. São a partir dessas parcerias que as escolas entram como um espaço potente na transformação de práticas consideradas inseguras para a manutenção da saúde e no conviver tolerante às diferenças. Verifica-se que nesse critério é necessário maior desenvolvimento de atividades entre os municípios elencados no estudo.

Aspectos a serem ponderados para a redução das violências são a prevenção do uso de drogas e a promoção da cultura de paz, sendo o primeiro importante para o segundo. Essas ações são apontados em cinco (05) e dois (02) municípios, respectivamente, como tendo ações direcionadas.

Ações com ocorrências relativamente significativas foram àquelas voltadas para as avaliações nutricional e oftalmológica que ocorreram, respectivamente, em dez (10) e oito (08) municípios. Cabe ponderar que apesar da expressividade dessas informações, algo pontuado como importante por um coordenador municipal foi que as ações, muitas vezes, existem, identificam-se problemas, mas não apresentam resolutividade por não contar com recursos suficientes para isso.

0 ML evidencia que um (01) município realiza controle do calendário vacinal nas escolas. Ainda provoca reflexão a não menção de atividades desenvolvidas nos municípios no que se referem à avaliação psicossocial, estratégias promotoras de atividade física e de controle do tabagismo.

Instiga-se a refletir sobre a invisibilidade dessas três ações. Estariam os municípios desconsiderando de que escolares não se expõem a riscos com implicações psicossociais? Está sendo negligenciado o potencial da atividade física enquanto estratégia para o enfrentamento de desvios nutricionais e situações de estresse tão na comunidade de escolares?

\section{...atitudes interdisciplinares \\ (...) essencial aos movimentos de educação permanente...}

Os riscos e acesso ao tabagismo pelos adolescentes estariam sendo naturalizados?

A inclusão de temáticas relacionadas à saúde e bem-estar foi mencionada como realizada em um (01) município. Isso pode ter influência da ainda distante articulação entre os setores educação e saúde nos municípios estudados; esta é apontada pelos informantes-chave como frágil nos treze (13) municípios participantes do estudo.

A atuação intersetorial na realização das ações do PSE foi identificada no estudo como necessária ao alcance dos resultados esperados pelo programa. Embora o Decreto $n^{\circ} 6286$ de 05/12/07, que institui - PSE, aponte, especificamente, que as equipes de Saúde da Família juntamente com a Educação Básica devam desenvolver estratégias para a integração e a articulação permanente entre as políticas e ações de educação e de saúde ${ }^{13}$, ainda há o que progredir. A falta de habilidade de desenvolver atividades conjuntas com outras categorias profissionais dificulta o diálogo e a atuação interdisciplinar.

Para haver essa interação é necessário inicialmente que dois ou mais profissionais tenham o interesse de interagir e compartilhar seus conhecimentos e saberes em prol de uma unidade e um objetivo comum. Essas trocas geram uma nova configuração interna, que, se ouvida e entendida, cria a possibilidade de atitudes interdisciplinares ${ }^{14}$. Isso é essencial aos movimentos de educação permanente que devem existir para a eficácia do PSE no estado, pois estes ainda se apresentam discretos nos municípios; sendo verificado em apenas seis (06) dos municípios estudados.

\section{Matriz de Análise e Julgamento}

0 processo de construção da Matriz de Análise e Julgamento deu-se a partir da identificação dos elementos que constituem a Matriz (Quadro 1), e suas respectivas definições. Esta produção foi realizada levando em consideração as características individuais 
dos componentes do PSE devidamente apresentados no ML.

Quadro 1 - Elementos componentes da Matriz de Análise e Julgamento do Programa Saúde na Escola no estado do Ceará, 2015.

\begin{tabular}{lr}
\hline Elementos da matriz & Definição \\
\hline Componente & Palavras-chave que agregam um conjunto de atividades do modelo lógico. \\
Indicador & Medida ou fator quantitativo ou qualitativo da expressão do componente a \\
ele relacionado.
\end{tabular}

Padrão Um valor de referência para mensuração de cada indicador.

Fonte de verificação Lugar onde os dados serão coletados.

\begin{tabular}{c} 
Valor de referência para o julgamento. Foi atribuído um indicador com valores \\
variando entre 10 (dez), 5 (cinco) e 2 (dois), sendo que o valor dois \\
corresponde ao padrão não atingido, o valor 5 corresponde ao padrão \\
parcialmente atingido e o valor 10 significa que o padrão foi atingido em sua \\
plenitude. \\
Julgamento corte $\quad$ É uma qualificação dada aos subcomponentes e à política na sua dimensão \\
\hline
\end{tabular}

Fonte: Adaptado de Bezerra et al (2012, p. 887)3

Assim, com base no ML, elegeram-se os indicadores para a Matriz de Análise e Julgamento apresentada no Quadro 2. Na Matriz é considerado o que deve ser avaliado e com base em que parâmetros, elencando-se para cada componente do ML os indicadores e os padrões relacionados aos recursos, ações e produtos. Têm-se ainda as fontes de verificação nas quais as informações de cada indicador devem ser buscadas e os pontos de corte para efeito de julgamento. 


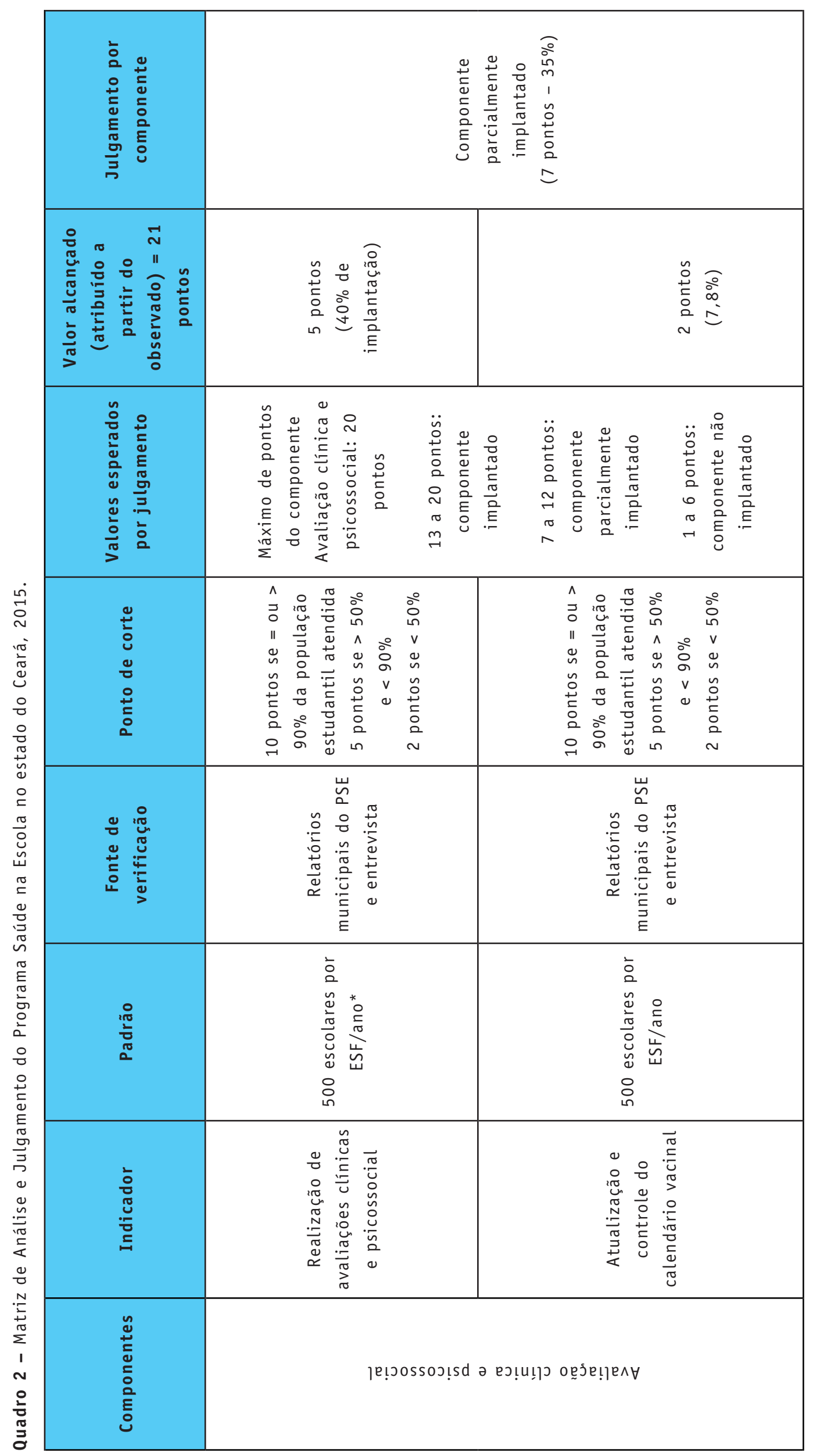

38 - SANARE, Sobral-v.17, n.01,p.32-42, Jan./Jun. - 2018 


\begin{tabular}{|c|c|c|c|c|}
\hline \multirow{2}{*}{ 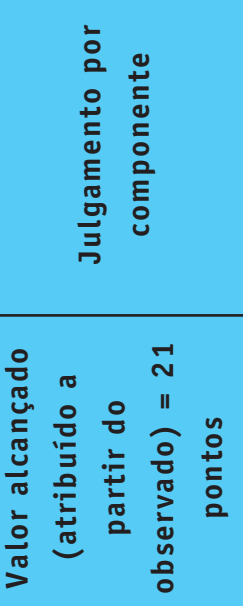 } & \multicolumn{4}{|c|}{ 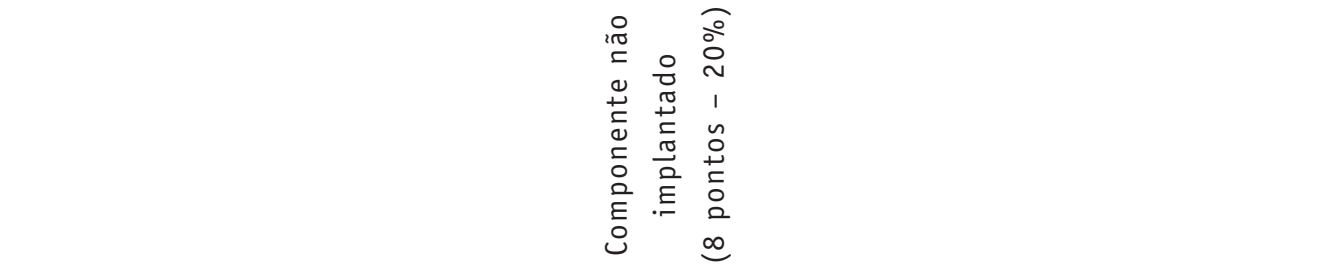 } \\
\hline & 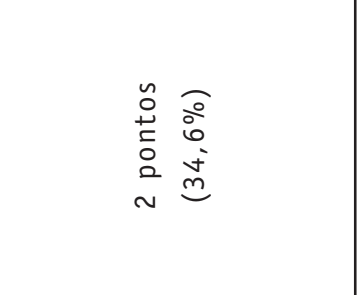 & 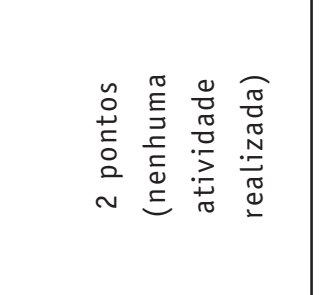 & 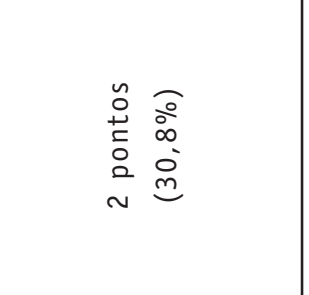 & $\begin{array}{ll}\tilde{O} & \widehat{o} \\
+ & \vdots \\
\check{0} & \vdots \\
0 & 0 \\
\sim & \pm\end{array}$ \\
\hline 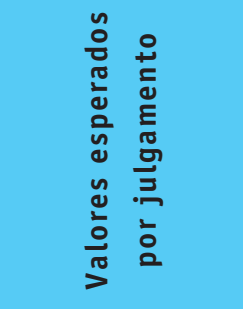 & \multicolumn{4}{|c|}{ 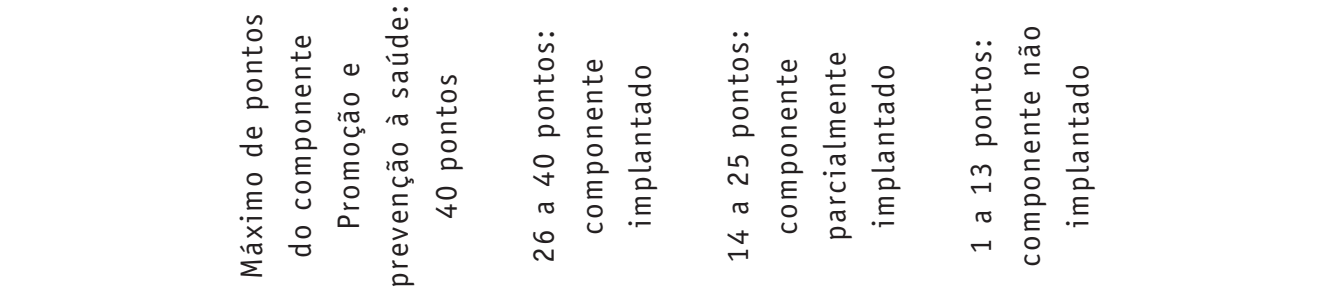 } \\
\hline \begin{tabular}{l}
0 \\
\multirow{2}{0}{} \\
0 \\
0 \\
0 \\
0 \\
+ \\
0 \\
0
\end{tabular} & 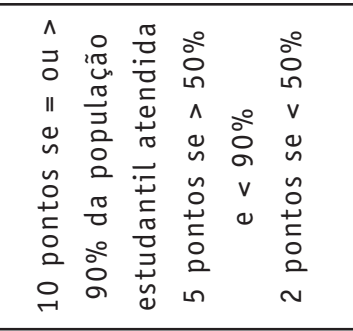 & 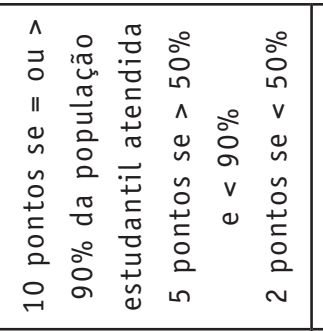 & 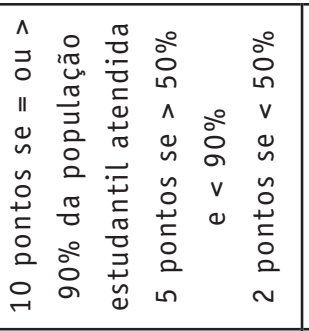 & 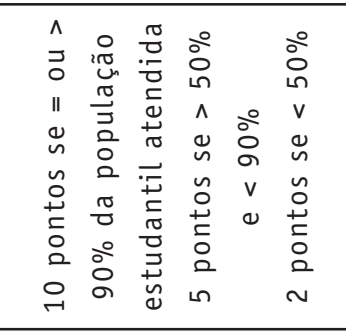 \\
\hline 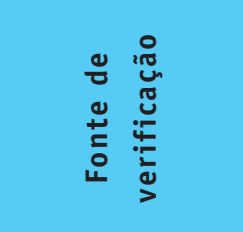 & 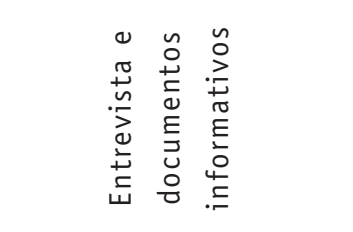 & 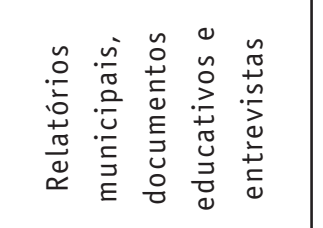 & 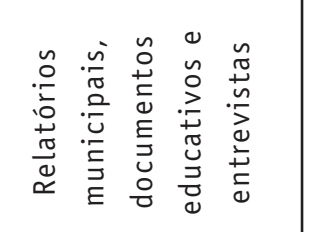 & 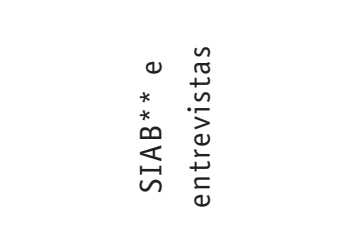 \\
\hline $\begin{array}{l}\frac{0}{\pi} \\
\frac{\pi}{\pi} \\
\frac{\pi}{0}\end{array}$ & 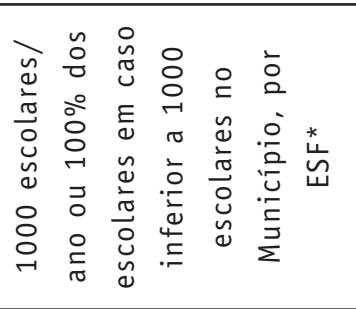 & 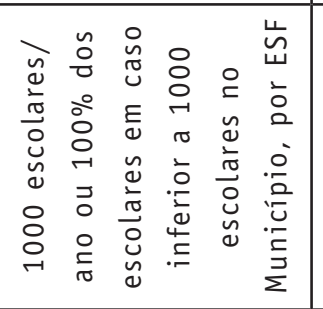 & 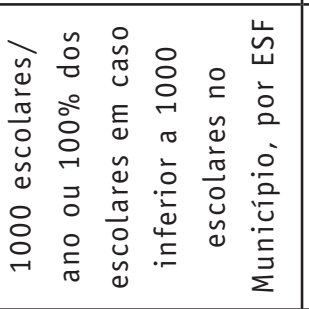 & 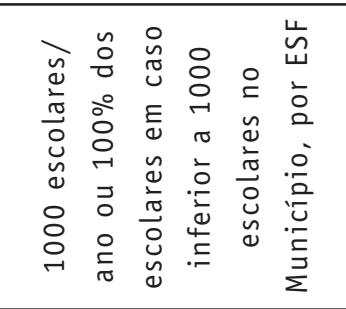 \\
\hline 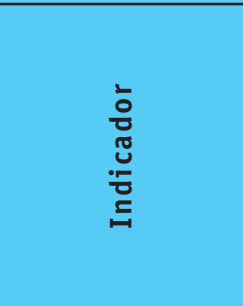 & 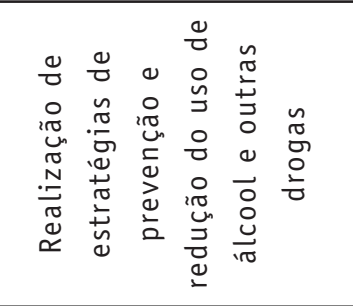 & 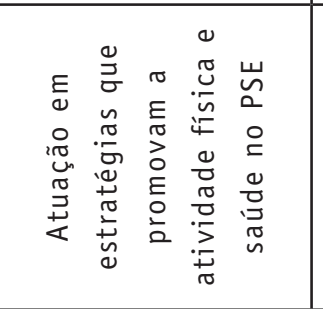 & 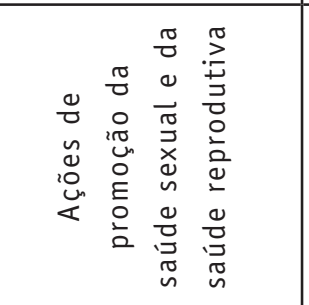 & 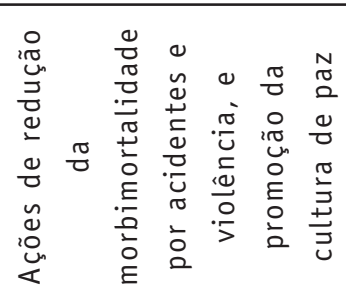 \\
\hline 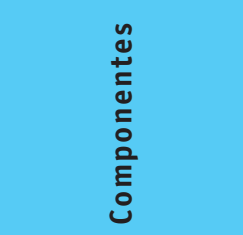 & & 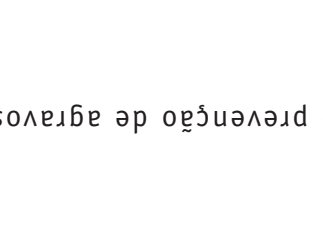 & әpnes ep opjomold & \\
\hline
\end{tabular}




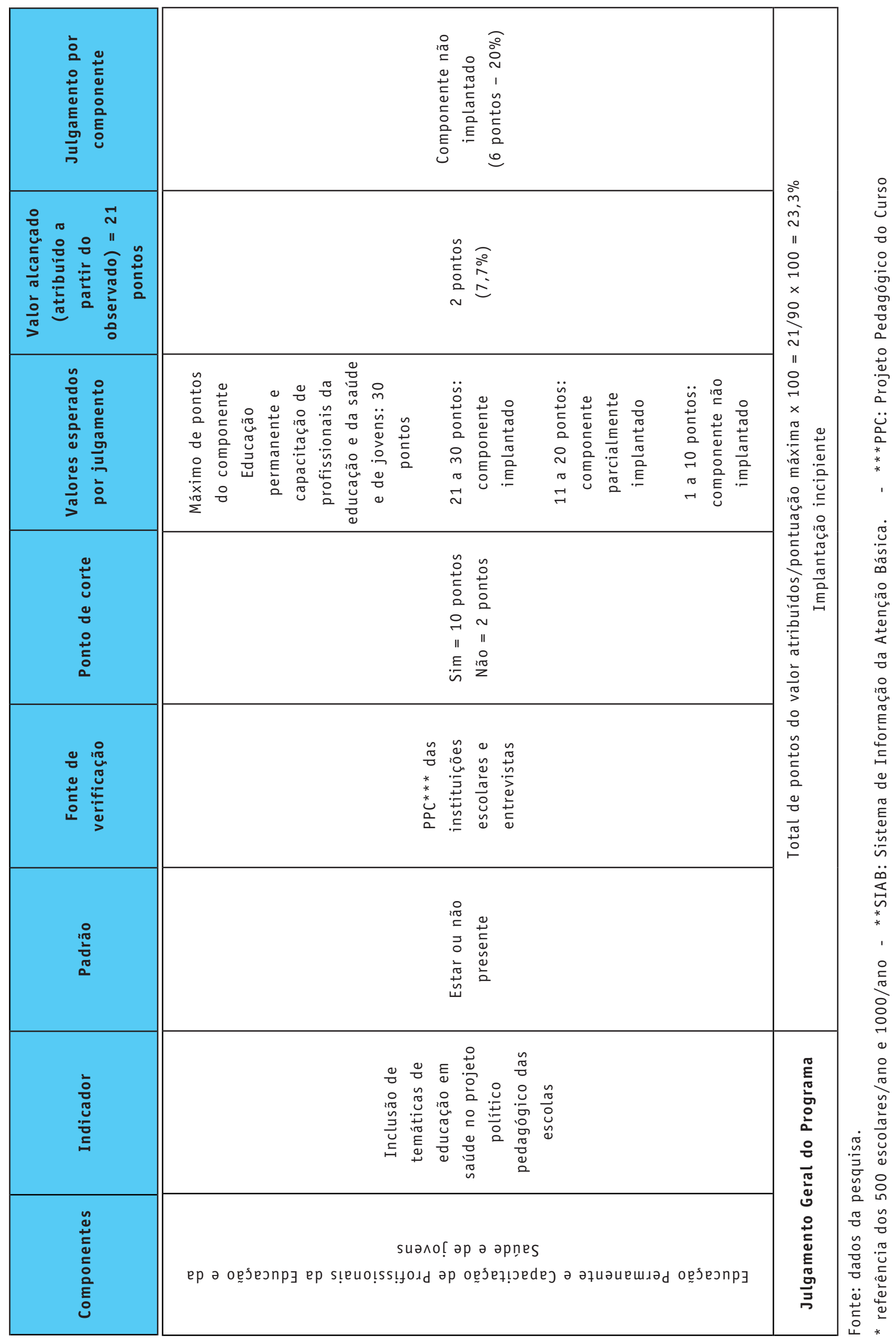

40 - SANARE, Sobral - v.17, n.01,p.32-42, Jan./Jun. - 2018 
0 julgamento constante na Matriz (Quadro 2) foi realizado segundo o valor atribuído, que se refere à categorização na qual aquele item estudado será enquadrado, e considerando a quantidade de estratos em sua composição. Adotou-se a divisão em tercis, que propõe os seguintes intervalos para julgamento: De $66,6 \%$ a $100 \%$ - implantação satisfatória ou plena; De $33,3 \%$ a $<66,6 \%$ - implantação parcial ou média; e, de $1 \%$ a $<33,3 \%$ - implantação incipiente ${ }^{10}$.

A Matriz aponta que muito há que se avançar com vistas à implantação adequada do PSE no Ceará. Ao analisar cada componente individualmente foi possível verificar que apenas o componente "Avaliação clínica e psicossocial" apresenta pontuação que o coloca como parcialmente implantado; os demais, "Promoção da saúde e prevenção de agravos" e "Educação permanente e capacitação de profissionais da educação e da saúde e de jovens", apresentam-se como componentes não implantados.

Considerando que a implantação do PSE prevê uma articulação de diversas ações de promoção da saúde na escola, envolvendo avaliação das condições de saúde dos estudantes, prevenção de agravos, formação de profissionais, monitoramento do PSE, dentre outros aspectos ${ }^{15}$. 0 exposto apresentado pela Matriz direciona para uma implantação incipiente do PSE no Ceará, que dialoga com o percebido no ML no sentido de compreender aspectos que dificultam sua implantação.

\section{CONCLUSÃO}

0 Programa Saúde na Escola, como uma estratégia de produção social da saúde, está contribuindo para o enfrentamento das vulnerabilidades que comprometem o pleno desenvolvimento dos estudantes brasileiros. 0s resultados ainda são incipientes, mas representam uma iniciativa potente dos gestores federal, estaduais e municipais na execução de políticas públicas voltadas a esse importante segmento, a partir de uma articulação interministerial.

0 PSE constitui uma possibilidade de suprimento de uma necessidade há tempos discutida: o fortalecimento da integração entre os setores educação e saúde, promovendo a intersetorialidade e a corresponsabilização entre estes setores, habituados a trabalhar isoladamente. Contudo ainda se faz necessário uma reflexão crítica de todo o seu processo, haja vista, que este pode não estar correspondendo plenamente ao proposto inicialmente.

Consideramos que o presente estudo atingiu seus

\section{O PSE constitui uma possibilidade de suprimento de uma necessidade há tempos discutida...}

objetivos no sentido de apontar e mensurar áreas da saúde estudantil que precisam ser melhor identificadas e cuidadas. Por conseguinte, a identificação dos indicadores apontados no estudo, pode-se ser importante no reconhecimento de áreas prioritárias que devem ser definidas para a avaliação.

A construção do Modelo Lógico evidenciou os componentes, recursos, ações, produtos, resultados intermediários e resultado final, bem como, os fatores limitantes que configuram o PSE no Ceará. Cada uma das ações foi exibida com a mensuração das suas respectivas taxas de execução, isso foi importante para mostrar-nos o quanto está sendo executado no Programa. Insuficiência nos processos de educação permanente, participação comunitária incipiente, defectível consolidação dos dados, poucos profissionais ativos no programa e diferentes prazos de consolidação dos dados para os setores saúde e educação, foram apontados como os fatores limitantes que precisam ser trabalhados no sentido de eliminálos ou atenuá-los para que os objetivos do PSE sejam alcançados.

Entendemos que a construção do modelo lógico e da matriz de julgamento do PSE no Ceará pode ser um importante subsídio pré-avaliativo para 0 desenvolvimento de estratégias que sejam capazes de aprimorar as ações que já vem sendo executadas e estabelecer outros possiveis caminhos que culminem na melhoria da qualidade de vida dos estudantes, e isso proporcione o pleno desenvolvimento dos jovens estudantes brasileiros.

É importante ressaltar que o tanto o Modelo Lógico quanto a Matriz de Critérios e Julgamentos do PSE, no Ceará, pode ser revisado a qualquer tempo, à medida que novas informações forem sendo coletadas e incorporadas ao desenho do Programa.

\section{CONTRIBUIÇÃO DOS AUTORES}

Maria Socorro de Araújo Dias, Lielma Carla Chagas da Silva e Maria da Conceição Coelho Brito contribuíram com o delineamento e realização da 
pesquisa, a redação do manuscrito e revisão crítica do manuscrito. Alexandro do Vale Silva, Rayanne Branco dos Santos Lima, Diógenes Farias Gomes contribuíram com a pesquisa e redação do manuscrito. Angelo Brito Rodrigues contribuiu com 0 delineamento da pesquisa e revisão crítica do manuscrito.

\section{REFERÊNCIAS}

1. Brasil. Ministério da Saúde. Gabinete do Ministro. Portaria $n^{\circ}$ 154, de 24 de janeiro de 2008. Cria os Núcleos de Apoio à Saúde da Família - NASF. Diário Oficial da União, Poder Executivo. Brasília: Ministério da Saúde; 2008.

2. Brasil. Ministério da Saúde. Programa Saúde na Escola, 2010. [acessado $2013 \mathrm{dez}$ 02]. Disponível em: http://dab. saude.gov.br/programa saude na escola.php

3. Bezerra LCA, Alves CKA, Reis YAC, Samico I, Felisberto E, Carvalho ALB et al. Identificação e caracterização dos elementos constituintes de uma intervenção: pré-avaliação da política ParticipasUS. Ciênc. saúde coletiva. 2012; 12(4):883-900.

4. Tanaka OU, Tamaki EM. 0 papel da avaliação para a tomada de decisão na gestão dos serviços de saúde. Ciênc. saúde coletiva. 2012;17(4):821-28.

5. Ceará. Seminário fortalece ações da política de saúde na escola [internet]. 2012. [citado em 2014 abr 13]. Disponível em: http://www.ceara.gov.br/index.php/sala-de-imprensa/ noticias/6066-seminario-fortalece-acoes-da-politica-desaude-na-escola

6. Lima LRF, Vieira-da-Silva LM. Ampliação do acesso à atenção oftalmológica: um estudo sobre a avaliabilidade da campanha "De Olho na Visão", Goiás, 2004. Ciênc. saúde coletiva. 2008;13(Sup 2):2059-64.

7. IPECE. Instituto de Pesquisa e Estratégia Econômica do Ceará. Nota técnica $n^{0}$ 18: taxa de vulnerabilidade social dos municípios cearenses. Fortaleza; 2006.

8. Ceará. Secretaria de Saúde. Microrregiões de Saúde [Internet]. 2014 [citado em 2014 jun 10]. Disponível em: http://geolivre.saude.ce.gov.br/egroupware/sitemgr/ sitemgr-site $/$ ?page name=Microregioes .

9. Bezerra LCA, Cazarin G, Alves CKA. Modelagem de programas: da teoria à operacionalização. In: Samico et al. (0rg.). Avaliação em saúde: bases conceituais e operacionais. Rio de Janeiro: Medbook; 2010. p. 65-78.

10. Telles PR, Buchele F. Redução de danos. In: Prevenção ao uso de drogas: curso de capacitação para conselheiros municipais. Brasília: Secretaria Nacional Antidrogas, 2008.
11. Samico I, et al $(0 \mathrm{rg})$. Avaliação em saúde: bases conceituais e operacionais. Rio de Janeiro: Medbook, 2010. p 89-105.

12. Anjos RMP, Rodrigues JMS, Rodrigues MP, Simoneti FS, Cunha L0. Acidentes e violências, vulnerabilidade e fortalecimento da rede de proteção: morbimortalidade no município de Sorocaba, São Paulo, Brasil. Rev. Fac. Cienc. Med. Sorocaba. 2015;17(2):62-8.

13. Brasil. Presidência da República. Decreto $n^{\circ} 6.286$, de 05 de dezembro de 2007. Institui o Programa Saúde na Escola (PSE), e dá outras providências. Diário Oficial da União. Brasília: Poder Executivo, 2007.

14. Maia DB, Sousa ETG, Gama RM, Lima JC, Rocha PCF, Sassaki Y. Atuação interdisciplinar na Atenção Básica de Saúde: a inserção da Residência Multiprofissional. Saúde transform. Soc. 2013;4(1):103-10.

15. Machado WD, Oliveira KMCP, Cunha KG, Araújo Júnior DG, Silvino RHS, Dias MAS. "Programa Saúde na Escola": um olhar sobre a avaliação dos componentes. Sanare (Sobral, Online) [serial on the internet]. 2016 [cited 2018 jan 16]; 15(1): 62-8. Available from: https://sanare.emnuvens.com. br/sanare/article/view/929/558
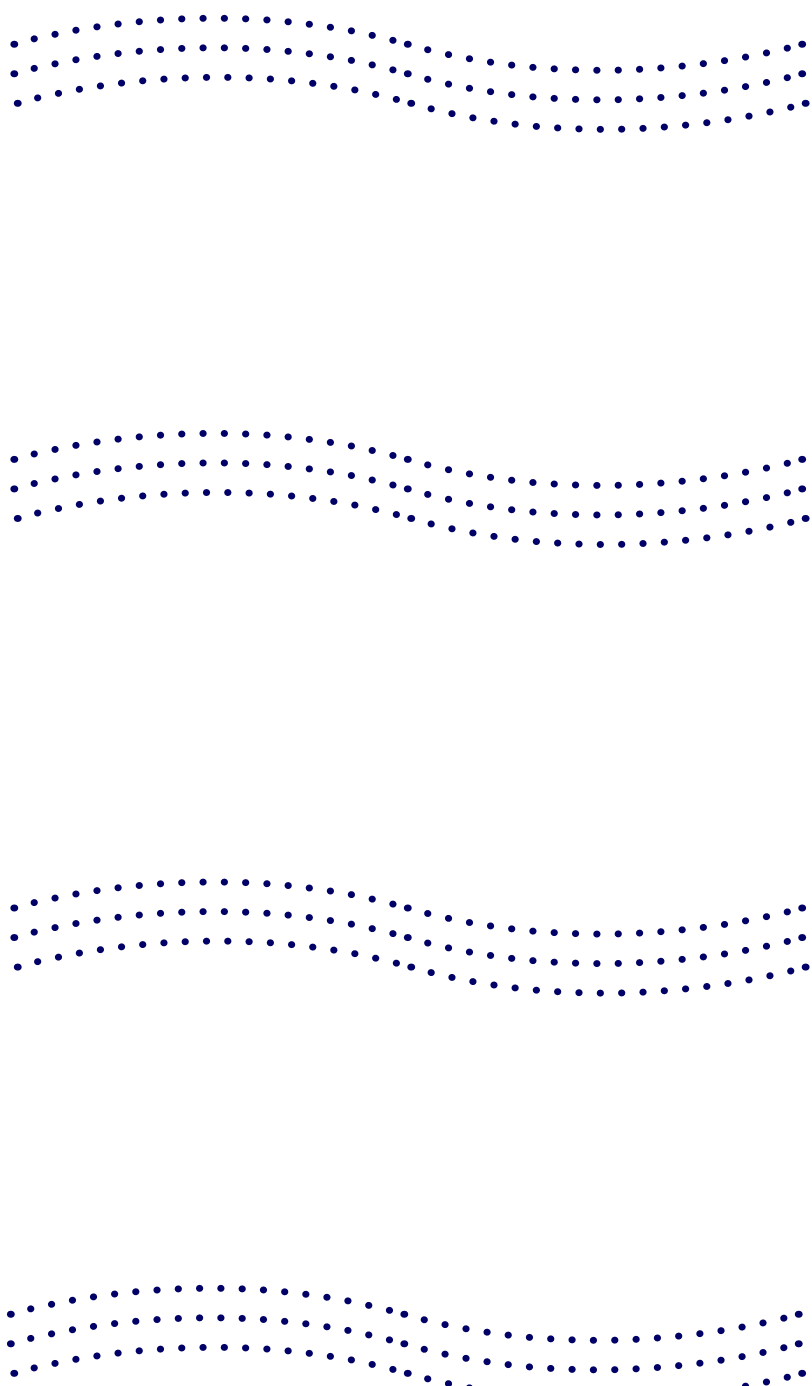